Article

\title{
Figures of the Earth: Non-Human Phenomenology in Joyce
}

\section{Ruben Borg}

The English Department, The Hebrew University of Jerusalem, Mount Scopus, Jerusalem 91905, Israel; ruben.borg@mail.huji.ac.il

Received: 4 August 2017; Accepted: 5 September 2017; Published: 7 September 2017

\begin{abstract}
My paper addresses the non-human turn in Joyce's work from the perspective of genetic phenomenology. I begin by commenting on Joyce's characterization of Molly Bloom as a non-human apparition. I unpack the notion of a non-human apparition in light of Joyce's interest in the idea of the earth as a generative matrix, and I relate this idea to a genetic enquiry into problems of passive synthesis and the givenness of objects to sense perception. I then trace the elaboration of this theme in a cluster of rhetorical figures from the later novels-puns, clichés, and metonymic associations - that play on the senses of matrix, materiality, and the sex of the mother. The second part turns to representations of the earth in Finnegans Wake. Focusing on scenes of interment and becoming one with the landscape, descriptions of tombs as echo chambers, and of geological sites as giant human bodies, I read Joyce's earth as the crowning expression of his experiments with a radical (pre- and post-human) phenomenology.
\end{abstract}

Keywords: earth; figuration; sense perception; prehuman and posthuman; passive synthesis; Joyce

In a letter to Harriet Shaw Weaver, dated 8 February 1922, Joyce lays out the program of a radical, modernist contribution to phenomenology. Speaking of the symbolic identification of Molly with Penelope in the last chapter of Ulysses, he writes: "I have rejected the usual interpretation of her as a human apparition-that aspect being better represented by Calypso, Nausikaa and Circe, to say nothing of the pseudo Homeric figures. In conception and technique I tried to depict the earth which is prehuman and presumably posthuman" (Joyce 1957, p. 180). Set forth in this statement are three key coordinates for a discussion of the later work: first, a somewhat stereotypical association of the female body with the earth; second, an allusion to a dimension of time that extends far beyond human experience, pre-dating human memory and exceeding projected lifespans; and third, an intuition that through conceptual and technical innovation one is able, after all, to imagine a mode of appearing and of being in the world - a phenomenality—that remains irreducible to any act of consciousness or apperceptive faculty.

The first of these propositions - the association of Molly with the earth-touches on questions of corporeality and material transformation. Joyce makes the point in response to Weaver's complaint that the character of Molly seemed to her almost primitive-hence "prehuman"—in its coarse physicality. He counters the critique by suggesting that the character be viewed as a stand-in for matter itself, matter regarded in its primordial, generative element. In turn, this understanding of primordial matter is complicit with a pre- and post-human articulation of time, and lays the groundwork for a new order of figuration.

My object in this essay is to unpack the concept of a non-human apparition in Joyce; and to discuss the effects of a pre- and post-human mode of figuration in his work from the perspective of genetic phenomenology. In appealing to the concepts and concerns of phenomenology, my reference is to the legacy of the later Husserl, the author of a new transcendental aesthetic first glimpsed in the Analyses Concerning Passive and Active Synthesis. It is during this phase that Husserl's focus begins to shift from 
an interest in the pure logical description of the workings of consciousness to problems of genesis and emergence, that is, to an interrogation of the conditions by which objects come to attention-of the manner by which they are given as already there, able to carry within themselves the memory of their constitution. ${ }^{1}$ Coming in the wake of his analysis of time-consciousness, and taking stock of the aporias engendered by his own account of the temporal dimension of phenomenal experience, the turn to a genetic method coincides with the intuition that the living present (the underlying temporal form of intentional consciousness) must be seen to have its own constitutive horizon. ${ }^{2}$ The analysis of passive synthesis thus seeks to thematize a kind of absolute, immemorial past, a phenomenological ground more primordial than intentionality. ${ }^{3}$

It is at the point, too, that Husserl's thought confronts its empiricist limit. As Paul Ricoeur has noted, "in becoming more and more existential the phenomenology of the late Husserl became more and more empirical, for the whole order of understanding - predicative judgement, affirmation and negation, activity of synthesis and consecution-henceforth proceeds from 'passive synthesis' initiated on the very level of perception" (Ricoeur 1967, p. 205). Here we might attempt a brief point-by-point summary of the broader applications of Husserl's concept of passivity. A little reductively, perhaps: (1) the discussion of passivity in the later work opens onto a regressive investigation of the workings of sense perception; (2) it delineates the outer limits of the ego as it relates to others and actively intends the world; (3) it is bound up with the theme of an infinitely receding past and attaches to a pre-predicative dimension of experience; and (4) it accounts for the constitution of material reality in so far as this is perceived as already there or pre-given. ${ }^{4}$

Without implying any direct indebtedness to Husserl, I wish to suggest that Joyce's declared intent to think through the peculiar phenomenality of the earth rests on these same passive-genetic principles. Crucial to Joyce's project, as we will see, is a series of rhetorical figures that revolve around the theme of the earth as a generative matrix. Most prominent among these is a cluster of puns on the mother's sex-the sex as delta, the womb as tomb, pussy_figures that are reinforced, in turn, by a set of recurring images and associations having to do with the motions of the earth and the nature of sense perception. It is important, in this context, not to misconstrue the identification of Molly with the earth as an instance of personification. At issue is not an anthropomorphic rendering of some primordial substrate of human experience, but rather the tracing—or the mobilization—of a pre-predicative process of constitution and synthesis: a genetic phenomenology in puns.

\section{The Pussens and the Earth}

I will begin by looking at the figure of the pussens as the site of an arbitrary, metonymic association between Molly and the earth. Critics have remarked on the psychological implications of the role of the

1 On the distinction between static and genetic models of phenomenological enquiry, see the Cartesian Meditations (Husserl 1982); in particular §§ 34-39. Here, Husserl also provides the clearest distinction between two types of constitutive genesis-the passive and the active.

2 "By the phenomenology of genesis attending to original becoming in the temporal stream, which itself is an originally constituting becoming, and by attending to the so-called 'motivations' that function genetically, a phenomenology of genesis shows how consciousness arises out of consciousness, how constitutive accomplishments are also continually carried out here in the process of becoming; thus it shows the relation of conditionality obtaining between the motivating and the motivated or the necessary transition from impression into retention, in which is constituted the consciousness precisely of this becoming, and correlatively of the alteration of the Now into a Now that is just past" (Husserl 2001, p. 644).

3 As A.J. Steinbock observes "passivity indicates a primordial regularity of sense-genesis in which the ego does not participate; it characterizes a pre-reflective dimension of experience of pregivenness of objectlike formations, a dimension that is founding for activity. Discerning such a sphere of passivity (and its implicit relation to activity) Husserl is able to describe the motivation from the passive to the active spheres under the rubric of fundamental laws of association" (Steinbock 2001, p. xliii). Husserl speaks, to this effect, of a peculiar work of synthesis occurring before the activities of the ego have come into play. This is "perception's proper and potentially purely passive course [...] Perception has its own intentionality that as yet does not harbor anything of the active comportment of the ego and of its constitutive accomplishment" (Husserl 2001, p. 94).

4 Thus, in the Cartesian Meditations: "The 'ready-made' object that confronts us in life as an existent mere physical thing [ ... ] is given, with the originality of the 'it itself', in the synthesis of a passive experience" (Husserl 1982, p. 78). 
cat in the Bloom household, highlighting its role as a site of displaced emotion between Leopold Bloom and his wife. In particular, Maud Ellmann notes that the language employed by Bloom in talking to the cat intimates a symbolic substitution (in his mind) between her and Molly, a case of "displaced tenderness" (Ellmann 2006, p. 76). Still more persuasively, Cheryl Herr draws an extended parallelism between the scene in the kitchen and the later exchange between Bloom and Molly, suggesting that "the feline and the female share a quality that the book is working hard to capture" (Herr 1987, p. 27). While I do buy into these arguments, I regard the pussens rather as a cipher, a signpost within a series of figures in which the theme of the earth as a sexualized matrix is more or less subtly encoded.

The first thing to consider is the character of figuration in Ulysses: pre-predicative, irreducible to intentional consciousness, passive in the narrow sense outlined above. Henry Staten provides a powerful model by which to understand the connection between Joyce's figural strategies and the cyclical movement of the earth intended as a ground of experience more primordial than any act of consciousness. As he points out, figuration in Joyce consistently foregrounds processes of composition and decomposition, and is often paired, as a result, with a metaphorics of eating, digestion, and defecation.

Every aspect of organic life-especially sexuality—is comprehended in Ulysses as a moment or aspect of a general circulation whose primary figure is eating and the digestive process... (Staten 1997, p. 384)

I would argue that this peculiar treatment of the figure points to the foundation of a new phenomenology, replacing thought (and by extension, the intentional form of subjective consciousness) with digestion (what Staten terms the "general gastronomics" (Staten 1997, pp. 384-85) of Ulysses), and substituting apperception with a pre- and post-human matrix. Within this conceptual framework the cat has a dual value. On the one hand, it is an example, same as any other animal, of organic, sentient but nonhuman life. Its role, in this sense, is no different than that of the minnows that pick at the drowned man's corpse in "Proteus" $(U 63)^{5}$, or the "obese grey rat" (U 145) Bloom spots among the graves in "Hades": to participate in the cycle of organic transformation, proceeding from birth to burial, from individual creature to decomposing body, eating and producing waste; and, in so doing, to offer a Copernican challenge to the philosophical grammars that traditionally grant human consciousness a place of privilege among all organic forms. But on the other hand, the cat also adds an identificatory dimension to this movement. More recognizable than the rat or the minnows, it brings special difference closer to home.

In turn, this recognizability is of two types. In the first place, it speaks to the cat's status as a domestic animal, a creature whose actions are instinctive but also habitual and well-practiced. Bloom's cat behaves like any cat, like my cat, like other cats in Joyce. Its first appearance ("The cat walked stiffly round a leg of the table with tail on high" [U 65]) has a degree of familiarity, and a communicative force, which "The grey alive crushed itself in under the plinth, wriggled itself in under it" (U 145) simply doesn't. Then again, Bloom also recognizes the cat itself, as an individual creature: "O, there you are, Mr Bloom said, turning from the fire" (U 65).

These distinctions allow us to map out the middle-ground of human/animal interaction in Ulysses - the special boundary onto which the traditional function of thought is displaced-along the following lines:

1. Humans and animals all participate in the organic cycle of birth and burial, eating and defecating, coming from the earth and going back to the earth;

2. Bloom and his cat interact within a shared domestic sphere, projecting desires, making demands of each other, using stock expressions, punctual gestures, vocal cues, drawn from instinct as much as habit. 
And there is a third hand too. Just as the cat signals its intention to leave the kitchen, mewing and waiting by the door, Bloom feels the need to visit the outhouse. His response to the cat's appeal ("Let her wait. Has the fidgets ... Wait till I'm ready" [U 82]), reads as a belated rejoinder to Molly's earlier exclamation, "what a time you were!" (U 76). The identification of the cat with Molly (noted by Ellmann and Herr) inscribes a sexual pun into the domestic routine, while the rest of the scene completes the chain of symbolic associations linking female sexuality with the cyclical motions of the earth.

Heaviness: hot day coming. Too much trouble to fag up the stairs to the landing.

A paper. He liked to read at stool. Hope no ape comes knocking just as I'm.

In the tabledrawer he found an old number of Titbits. He folded it under his armpit, went

to the door and opened it. The cat went up in soft bounds. Ah, wanted to go upstairs, curl

up in a ball on the bed.

Listening, he heard her voice:

-Come, come, pussy. Come. (U 82)

Bloom will be reminded of this moment in "Nausicaa", and it is worth remarking on the almost arbitrary intrusion of the memory — specifically, the image of the cat —in an otherwise tightly determined chain of associations, proceeding from sexual attraction to magnetism, to the magnetic pull of the sun upon the earth, to the link between the motions of the earth and time, to Molly's desire, to arousal and women's perfume (Rose or Hyacinth, misremembered as Heliotrope), to the cat and its habit of sniffing as it shifts on the bed, to the effects of sunlight on color, and the appearance of the cat upon the staircase, the "[c]olour of brown turf" (U 493).

The connection between the motions of the earth and the theme of female sexuality is quite obviously repeated in this later sequence, triggered by the coincidence of a wristwatch stopping at the fateful hour of Molly's appointment with Boylan. But what is the added value to the scene of an image that has the cat shifting on the bed and sniffing its own scent just like Molly does? And what of the surprising remark that sometimes, when the light falls in a certain way, the cat takes on the appearance of brown turf?

In A Portrait of the Artist, Uncle Charles retreats every morning to the "outhouse, which he share[s] with the cat and the garden tools" (P 62) ${ }^{6}$; and in Finnegans Wake, the charwoman Kate, Biddy Doran's feline alter-ego, is periodically seen haunting the mound behind HCE's tavern. Here too, the cat/earth association seems arbitrary, but the recurrence of the two elements in close juxtaposition is striking in and of itself (the cat digging by the rubbish heap, the cat and the garden tools, the cat and the outhouse). Returning to "Nausicaa" by way of these scenes, we discover a peculiar Joycean insistence on the realm of the senses, and, in particular, a synesthesia of smell and sound, on the one hand, and a fascination with color and light on the other. I would argue, in short, that the associative chain triggered by the breakfast routine, and brought to the fore again by the memory of the pussens on the staircase, is part of a broader Joycean concern with the genesis of sense perception-and that mobilized in the play of identifications is an attempt to think through the relation between the earth (its attendant figures) and the making of the sensible world.

\section{Sense Perception}

A Portrait of the Artist is a case in point: Uncle Charles's outhouse is described as "reeking" (P 62); but we are told that the place "served him also as a sounding-box" where "every morning he hummed one of his favourite songs" ( $P$ 62). The pungent smoke is from "black twist" tobacco ( $P$ 62); but it fills the air in "grey and blue coils" (P 62). Joycean physics, refined and reduced to minimal terms, comes back to the same set of questions: the ineluctable modality of the visible, of the audible, and of the

6 The reference (Joyce 2003) will be cited as $P+$ page number. 
olfactory. How are bodies formed? What makes them change? Does reality give itself differently to the ear than to the eye, or nose?

In Ulysses, the significance of the earth to these investigations is thematized explicitly. As in "Proteus", where Stephen reflects on the power of the tides to influence organic form, seaspawn to seawrack, tidal pool to drowned man's grave, so too in "Hades" and in "Nausicaa", Bloom contemplates the shifting of bodies-variations in color, the exchange of natural and artificial scent, the varying dispositions of the flesh coinciding with arousal and sexual exhaustion-and imagines the motions of the earth as the generative matrix underpinning all changes in the sensible world.

Two details, in particular, link the systematic review of the realities of the eye, ear and nose in the book's third episode (color vs. transparency; rhythm and alliteration; ashen breath and snot), with the figure of a maternal earth. The first, and perhaps the more striking, is the image of an umbilical cord dragged across the sand, the cord turning into a telephone line, linking the present with an immemorial, prehuman past, ${ }^{7}$ while the second, alluded to in the previous paragraph, is Stephen's observation of the movement of the tides and its effect on organic life.

Listen: a fourworded wavespeech: seesoo, hrss, rsseeiss, ooos. Vehement breath of waters amid seasnakes, rearing horses, rocks. In cups of rocks it slops: flop, slop, slap: bounded in barrels. And, spent, its speech ceases. It flows purling, widely flowing, floating foampool, flower unfurling. Under the upswelling tide he saw the writhing weeds lift languidly and sway reluctant arms, hising up their petticoats, in whispering water swaying and upturning coy silver fronds. (U 62)

At issue here is the description of a sexualized earth; and from that premise, a patient fleshing out of the organic cycle of birth and burial, the world of matter coming into being, coming into focus, one sense at a time. Completing the picture, two paragraphs down, is Stephen's identification with the drowned man, hauled up from the depths, already part of the marine food chain.

Bag of corpsegas sopping in foul brine. A quiver of minnows, fat of a spongy titbit, flash through the slits of his buttoned trouserfly. God becomes man becomes fish becomes barnacle goose becomes featherbed mountain. Dead breaths I living breathe, tread dead dust, devour a urinous offal from all dead. Hauled stark over the gunwale he breathes upward the stench of his green grave, his leprous nosehole snoring to the sun. A seachange this, brown eyes saltblue. (U 63)

Twice Bloom responds to these fantasies (that of an umbilical cord running through the earth; and that of a sexualized earth-mother engendering the sensory world). The first time, in "Hades", as he watches on while gravediggers clean up a burial site, removing spades and blades of grass, and coiling a coffin band that reminds him of a "navelcord" (U 142); shortly thereafter, he imagines a technological device by which to keep the memory of the dead: not quite a telephone line connecting the present with past generations, but a gramophone inside the grave: "Kraahraark! Hellohellohello amawfullyglad kraark awfullygladaseeagain hellohello amawf krpthsth. Remind you of the voice like the photograph reminds you of the face" (U 144). The second occurs in "Nausicaa" when Bloom thinks about magnetism as the principle of all movement, and then rehearses the erotic implications of that idea.

What interests me in these passages is the evidence of a pattern beneath the apparent randomness of associations. From the earth as matrix (generative, sexualized, the origin and endpoint of organic

7 The pull of the earth is emphasized throughout the scene. Joyce describes the navelcord as "trailing" from a midwife's bag which "swung lourdily" (U 46), while the midwife herself appears to be "sinking in the silted sand" (U 46). The cord soon becomes a telephone that links back to Eve: "Hello. Kinch here. Put me on to Edenville. Aleph, alpha: nought, nought, one" (U 46); then, a few pages down, Stephen associates the movement of the tides with the image of Eve driven out of Eden: "She trudges, schlepps, trains, drags, trascines her load. A tide westering, moondrawn, in her wake" (U 60). 
life, and the ground of all change in the physical world), to a peculiar physics of the senses-eccentric and tentative, drawing on outdated scholastic principles in Stephen's case, and on an intuitive, sketchy knowledge of the science of motion in Bloom's. Thus in Hades, completing the grandpa on the gramophone skit: "A corpse is meat gone bad. Well and what's cheese? Corpse of milk. I read in that Voyages in China that the Chinese say a white man smells like a corpse" (U 145). In "Nausicaa", the focus is on sexual attraction rather than decomposition:

Earth for instance pulling this and being pulled. That causes movement. And time, well that's the time the movement takes. Then if one thing stopped the whole ghesabo would stop bit by bit. [...] Molly, her underjaw stuck out, head back, about the farmer in the ridingboots and spurs at the horse show. And when the painters were in Lombard street west. Fine voice that fellow had. How Giuglini began. Smell that I did. Like flowers. It was too. Violets. Came from the turpentine probably in the paint. (U 487)

The construction of the scene-the smell of the paint, combining with the singing voice of the painters, and, implicitly, the paint color-parallels the description of Uncle Charles smoking and singing in his reeking outhouse, and that of the tide's wavespeech turning into a drowned man's stinking green grave. In this case, an overlap of memory and desire supplies the connection between different stimuli (flowers... violets... a color and a voice you can smell).

Bloom's reference to heliotrope, on the same page, reinforces the pattern. The importance of this signifier in Joyce's body of work has been extensively discussed by critics, most notably by Margot Norris (1989) who unpacks its value as an overdetermined figure for desire, and argues that it cues an erotic discourse that regulates memory (Gabriel Conroy's, Bloom's) and shapes reading protocols from Dubliners to Finnegans Wake. We know that Bloom thinks of Heliotrope as a fragrance, first of all. But the word also denotes a color, and a type of flower that is susceptible to sunlight ("earth pulling this and being pulled"). The element of sound is provided, in turn, by the association of perfume notes with the "high notes" and "low notes" of Molly's art. Combining all these senses, Norris observes that heliotropic desire informs one of Joyce's most prominent meta-historical allegories: "the mystery of sexuality, offers [...] a vision of perdurable organic life surviving repeated colonizations with vigor and joy. Floral history is the dream antidote to an apocalyptic cultural history, and in it sexuality is history in the making, a ballet of pollination and procreation" (Norris 1989, p. 21).

\section{The Time the Movement Takes}

As is often the case in Joyce, the hardest element to account for is time. Bloom's idea that the pull of the earth is the cause of all movement in the sensible world is a straightforward enough proposition. The relation, as we have seen, is one of ground to percept, and of generative matrix to organic form and perceptible change. What, then, of time in relation to movement? As Bloom wonders, for an instant, about what might cause time (intending, presumably, what its nature might be and what might cause it to start and to stop), his train of thought seems to run itself into a circle. His answer, amounting to the pleonasm that time is "the time the movement takes", is no answer at all.

Katherine Ebury has shown that the treatment of color in Finnegans Wake-and, in particular, the motif of the rainbow-is bound up with an understanding of reality as multiple, complex and, at heart, obscure. "[T]hough colours and words do bleed together in the Wake, they are also split, as in 'the abnihilisation of the etym', to reveal new and plural realities" (Ebury 2014, p. 108). Paired with an idiosyncratic optics devoted to the spectral effects of light, Joyce's rhetoric inscribes an element of invisibility, of irreducible opacity right at the center of the visible.

The spectral strangeness and obscurity that the Wake exhibits and its presentation of alternate realities side by side (to give one example, its presentation of a world in which ALP can be a woman, a river and, at times, a hen) is linked to a notion of light's complexity as the text itself functions as a kind of spectroscope that reveals a hidden complexity and plurality within the everyday. (Ebury 2014, p. 108 ) 
The interrogation of time and movement in "Nausicaa" (and indeed through all of Joyce) shares something of this structure. Bloom's reflections on magnetism touch on a problem that has long haunted philosophy, the idea that time is fundamentally intractable to scientific or phenomenological enquiry, that it never gives itself to human consciousness, precisely because consciousness always already happens in time and presupposes time as its vanishing horizon. I have argued, elsewhere (see Borg 2007), that in grappling with this paradox Finnegans Wake draws extensively, in both style and theme, on Aristotle's definition of time as something that "either does not exist at all or [exists] barely and in an obscure way" (Aristotle 1941, § 218). Simply put, there is always too much past and too much future comprising the full measure of time at any given moment, too much of the immemorial and the unforeseeable distorting any attempt to reckon with time scientifically. What then of the time we associate with the revolutions of a pre- and post-human earth?

If we suppose, as Bloom does, that time is coextensive with the motions of the earth, then we do well to take note of the temporal coordinates that regulate, possibly predetermine those motions. In this case, "pulling this and being pulled" suggests a certain mutuality, or reciprocity. The phrase brings to mind a choreography, or a sexual act (and indeed erotic overtones are not out of place in the broader context of the episode). But in a narrower sense, "being pulled" has the significance of adding a passive dimension to the proceedings—an ability not only to produce perceptible change but to be affected by corresponding forces. This passivity, attributed to the very ground of perception, the constant source from which all change emerges, is indicative of an originary, impenetrable pastness always already part of the phenomenal world, a dimension of the visible and the audible, etc., that never gives itself to experience.

\section{Heated Residence}

In Finnegans Wake, the function of the earth as generative matrix and as ground of sense perception largely attaches to two figures: the mound, which is associated with the fallen body of HCE (typically accompanied by the threatening presence of Biddy Doran or Kate); and the mystery of the "eternal geomater" (FW 296-97) ${ }^{8}$ which is revealed to be the sex of ALP. ${ }^{9}$

Featured most prominently in Chapters 1 and 5, the mound is an important landmark in the Wake's topography, in effect a composite site that condenses three or four locations in one: a rubbish heap in HCE's backyard, in which all sorts of domestic artifacts are dumped and recycled; a hill by the magazine fort in Phoenix Park, doubling as a war museum dedicated to the Battle of Waterloo; and a barrow or a system of tombs, repurposed now and then, as a mausoleum. The thematic connection between the locations is established early on, as the book's overture moves swiftly from one to the other. The first occurrence easily goes unnoticed, but sets up an important refrain: as a result of the mythic fall that triggers universal history, our hero (HCE, Tim Finnegan, Finn MacCool, or Humpty Dumpty) is discovered flat on his back, wondering where his toes are. They turn up "at the knock out in the park where oranges have been laid to rust upon the green since devlinsfirst loved livvy" (FW 3). The motif is picked up a few pages down as we read, once again, that the giant's "clay feet, swarded in verdigrass, stick up starck where he last fellonem, by the mund [McHugh: mouth; mound] of the magazine wall" (FW 7).

"Verdigrass" suggests green grass, of course, but also verdigris, which, like rust, is both the name of a color and a metallic patina obtained through a process of oxidization. As in "Proteus", where colors are always viewed in the process of blending or changing, as though animated by ghostly-material effects, the figure of the mound seems to go hand in hand with descriptions of coloring and discoloration. By the same token, the image of the "oranges [that] have been laid to rust

8 The reference (Joyce 1992) will be cited as cited as $F W+$ page number.

9 For many of the glosses given in this section I am indebted to the annotations provided in McHugh (1991), and on the Fweet website designed and maintained by Raphael Slepon (Slepon 2017). I am also very grateful to the members of the Jerusalem Finnegans Wake Reading Group. 
upon the green" (disregarding for a moment the political allegory) connotes both a mixture of hues and a rubbish heap where rotting fruit mixes with grass and turf. This detail is picked up much later in the novel, during a pivotal episode when an incriminating letter, itself subjected to the corrosive effects of light and time, is recovered from the "mudmound" by Biddy Doran.

Heated residence in the heart of the orangeflavoured mudmound had partly obliterated the negative to start with, causing some features palpably nearer your pecker to be swollen up most grossly while the farther back we manage to wiggle the more we need the loan of a lens to see as much as the hen saw. Tip. (FW 111-12)

"Orangeflavoured" harks back to the picture of oranges rusting on the grass, while "Tip" reprises Kate's refrain during her guided tour of the "museomound" (FW 8). Similarly, "heated residence" reminds us of the temperature inside the museum ("Phew! What a warm time we were in there": $F W$ 10). But the most prominent detail concerns the treatment of the letter as a poorly developed photographic image. Crucially, it is the physics of coming into view, the process of emergence into the perceptual field, that is of interest to Joyce. That is to say, the document is examined, first of all, as an object given to sight. And because it is disfigured, damaged by too much heat and prolonged contact with "terricious matter" (FW 114), we are able to dwell on what, in a percept or an apparition, is normally not given to perception, the magic by which the image itself is produced in all its materiality: time and light.

It is in connection with the mound, too, that the smells and sounds of the earth are first invoked. Reimagined as a war museum, the rubbish heap becomes a metonym for all battlefields in history (many of them hills): the war-torn, disfigured landscape, identified with HCE's body, is "scentbreeched" and "somepotreek" (FW 12), while the system of graves and sedimented histories layered underground, is imagined as an echo chamber. Once again, Joyce invokes a bizarre technology to illustrate the relation between the motions of the earth and the phenomenality of objects in the world. "Dbln. W. K. O. O. Hear? By the mausolime wall. Fimfim fimfim. With a grand funferall. Fumfum fumfum. "Tis optophone which ontophanes..." (FW 13).

John Bishop reads these lines as evidence of Joyce's belief in the primacy of the ear over the eye. An optophone being an aid for the visually impaired that turns visual stimuli into sound, "Earwicker's 'optophone'-like ears" are described as "portals through which, in the dark, 'reality' (Gr. onta) and 'being' (Gr. ta onto, 'existing things') come to light (Gr. phaino, 'to bring to light, make to appear'): hence the verb 'ontophanes'"' (Bishop 1986, p. 287). I find the claim persuasive. Sound is indeed the main theme of the passage, and hearing the most prominent sense, but it is worth adding that the ear itself is a grotesquely overdetermined organ in Joyce, and further, that its ascendancy is always complicated by a conflation with other organs or a ghostly intrusion of competing stimuli. For instance, "Fimfim fimfim [...] Fumfum fumfum" denotes rhythmic strumming on a string instrument (presumably, a lyre); yet there is also a suggestion of masturbatory strumming, an insistence on shameful sexual spectacle, as well as a reference to smell in the motif "Fee-fi-fo-fum. I smell the blood of an Englishman. Be he alive or be he dead..."

Notably, the optophone is only one in a series of technologies of the grave alluded to in Joyce's work. I have already mentioned the gramophone in "Hades", and the umbilical cord turned telephone-to-the-departed in "Proteus". There are also suggestions of a radio transmission inside the mausoleum (FW 13). But the paradigmatic technology in this category, the one that expresses the full potential of all the others, is the seance kit (ouija board, unlicensed medium, and so on) employed in Book III of the Wake for the purpose of a posthumous interrogation of HCE. Here too, mound and earth metaphors feature prominently, alongside references to radio stations and sound equipment. The "hillock" (FW 474), or "molehill" (FW 474) on which Yawn, the medium, sits turns out to be "the same prehistoric barrow [...] the orangery" (FW 478) invoked in the opening pages; while Yawn himself is described as an "earthpresence" (FW 499), emitting far too much static and white noise (an analogue, this, of the spectral white light inside the rainbow, discussed by Ebury). 
Is the strays world moving mound or what static babel is this, tell us?

-Whoishe whoishe whoishe whoishe linking in? Whoishe whoishe whoishe? (FW 499)

"Whoishe" is first of all a question about the identity of the disembodied voice that speaks from beyond the grave. But it is also an onomatopoeic approximation of the very white noise it interrogates. (Note that the pronunciation of the last syllable is indeterminate, the morphology of the Wake allowing us to read it as either he or she.) We cannot make narratological sense of this utterance by attributing it to a specific speaking subject. It is at one and the same time a human word (spoken by one of the four old men), and a spectral sound, where "spectral" refers both to a ghostly presence producing the vibrations, and to the infra-sensory quality of the sound itself: a generative principle, a rhythm and a movement, by which the world is given.

\section{Being Given}

The identification of the earth with female sexuality is an explicit theme of the "Night Lessons" of Book II.2. The chapter contains one of the best-known set pieces of the Wake, in which the twins, featured as Dolph and Kev, are presented with a geometry problem the solution of which doubles as an anatomy of their mother's vulva. ${ }^{10} \mathrm{Kev}$ guides his brother through a step by step working of the problem, before daring him to peek under the mother's skirt: "Now, to compleat anglers, beloved bironthiarn and hushtokan hishtakatsch, join alfa pea and pull loose by dotties and, to be more sparematically logoical, eelpie and paleale by trunkles. [...] I'll make you to see figuratleavely the whome of your eternal geomater" (FW 296-97).

While the chapter is known as one of the densest of the Wake (and for good reason), the last phrase is not hard to unpack. Joyce's letter to Weaver alone provides a powerful annotation. To the concept of the earth as a pre- and post-human ground of existence, the word geomater adds the sense of the mother as the original geometer. Crispi has noted Joyce's hesitation in using the portmanteau word-which is included in an early draft, then replaced with geometer, then reinstated-reading into this an indication of Joyce's ambivalence about the role of the mother in the episode (Crispi 2007, p. 220). But it is possible Joyce felt, for a time at least, that geomater was too on the nose, and that the revelation of the mother as earth was to be more hardly earned by the twins and by the reader.

At any rate, the final draft settles on geomater, and I would argue that there is a tension encoded in that word choice, a subtle dualism, that is simply too rich to forgo. Where the myth of the earth-mother insists on material presence (with all the banalities that such an old chestnut entails), geometry suggests a principle of creation out of abstract, universal forms. The geomater, in short, combines pure, minimalist formalism with a natural, messy fecundity. But the tension in this case, is also between two versions of thought, and two operations of the figure: reductive abstraction on the one hand, and accumulation or total inclusiveness on the other.

The same tension is expressed as a contradictory movement in time. As the matrix of all things given in the world, the earth produces the very figures used for abstract thought out of its own body. The letters of the alphabet, the Wake tells us, are made of clay or mud, originally figurines left on the river bed; but they are also the tools which the twins must use to reconstruct the diagram of the "mudder" (FW 240, 496). Time flows "foriverever" (FW 242), from and towards the earth.

In this sense, too, the twins' diagram functions as a multilayered visual pun. The first layer is obvious enough: the sexual double-entendre associated with the triangle needs no explanation. But to this figure is added the conceit of a return to origins, an enquiry into the beginnings of organic life that somehow coincide with its very end: ALP and her triangle are also the alpha and delta, or if you will

10 The importance of the geometry lesson for the structure and overall conception of the novel has been amply attested by critics. See for instance Hayman (1990); and, for a definitive discussion of the compositional history, Crispi (2007). 
the aleph and daleth (the first and fourth letter of the Greek and Hebrew alphabets, reminding us that universal history, as Joyce understood it, unfolds as a four-part cycle).

While Joyce's interest in cyclical narratives is a well-digested staple of Wake criticism, the time that concerns us when speaking of a pre- and post-human earth is not historical at all. It is precisely the time of a back and forth movement, of an infra-sensory rhythm that underpins all changes in the sensible world, of pulling and being pulled.

Passivity and spectrality are key. The examples of human/non-human interaction examined above always run the risk of being misunderstood as instances of anthropomorphism or personification, that is to say, of being reabsorbed within a regressive order of figuration. True, there is nothing intuitively new, much less radical, about the notion that human form originates in dust and ends in dust. Nor is the association of the earth with female sexuality necessarily complicit with an interrogation of traditional phenomenological grammars. What raises Joyce's treatment of these themes above the order of cliché is his attention to the equiprimordiality of matter, figure, and letter, and to the passive articulations of the earth's movement in relation to the phenomenal world.

Conflicts of Interest: The author declares no conflict of interest.

\section{References}

Aristotle. 1941. Physics. In The Basic Works. Translated by R. P. Hardie, and R. K. Gaye. Edited by Richard McKeon. New York: Random House.

Bishop, John. 1986. Joyce's Book of the Dark. Madison: University of Wisconsin Press.

Borg, Ruben. 2007. The Measureless Time of Joyce, Deleuze and Derrida. London: Continuum.

Crispi, Luca. 2007. Storiella as She Was Wryt: Chapter II. 2. In How Joyce Wrote Finnegans Wake: A Chapter-by-Chapter

Genetic Guide. Edited by Luca Crispi and Sam Slote. Madison: University of Wisconsin, pp. 214-49.

Ebury, Katherine. 2014. Modernism and Cosmology: Absurd Lights. London: Palgrave.

Ellmann, Maud. 2006. Ulysses: Changing into an Animal. Field Day Review 2: 74-93.

Hayman, David. 1990. The Wake in Transit. Ithaca: Cornell University Press.

Herr, Cheryl. 1987. Art and Life, Nature and Culture, Ulysses. In Joyce's Ulysses: The Larger Perspective. Edited by Robert D. Newman and Weldon Thornton. Newark: University of Delaware Press, pp. 19-38.

Husserl, Edmund. 1982. Cartesian Meditations: An Introduction to Phenomenology. Translated by Dorion Cairns. The Hauge: Martinus Nijhoff Publishers.

Husserl, Edmund. 2001. Analyses Concerning Passive and Active Synthesis: Lectures on Transcendental Logic. Dordrecht: Kluwer Academic Publishers.

Joyce, James. 2003. A Portrait of the Artist as a Young Man. London: Penguin. First published 1916.

Joyce, James. 1960. Ulysses. London: Bodley Head. First published 1922.

Joyce, James. 1992. Finnegans Wake. London: Penguin Books. First published 1939.

Joyce, James. 1957. Letters I. Edited by Stuart Gilbert. London: Faber and Faber.

McHugh, Roland. 1991. Annotations to Finnegans Wake, revised ed.; Baltimore: Johns Hopkins University Press.

Norris, Margot. 1989. Joyce's Heliotrope. In Coping With Joyce: Essays from the Copenhagen Symposium. Edited by Morris Beja and Shari Benstock. Columbus: Ohio State University Press, pp. 3-24.

Ricoeur, Paul. 1967. Husserl: An Analysis of His Phenomenology. Translated by E. G. Ballard, and L. Embree. Evanston: Northwestern University Press.

Slepon, Raphael, ed. 2017. The Finnegans Wake Extensible Elucidation Treasury (FWEET). Available online: http:/ / www.fweet.org/ (accessed on 12 June 2017).

Staten, Henry. 1997. The Decomposing Form of Joyce's Ulysses. PMLA 112: 380-92. [CrossRef]

Steinbock, Anthony J. 2001. Translator's introduction. In Analyses Concerning Passive and Active Synthesis: Lectures on Transcendental Logic. Edited by Edmund Husserl. Dordrecht: Kluwer Academic Publishers. 